\title{
Monstruos prehumanos y supercíborgs en la narrativa de Lina Meruane
}

\author{
Elena Alonso Mira ${ }^{1}$
}

Resumen. La producción literaria de la escritora chilena Lina Meruane se interna en el valle de los monstruos e indaga en todos aquellos rincones donde pueden acechar. Este artículo analiza las diferentes representaciones del monstruo en la obra de la joven narradora de la mano de sus personajes: niñas y adolescentes, desobedientes y en busca de una identidad que pugna por no ser categorizada. Mártires ficcionales de un mundo real, las protagonistas de Las infantas (1998) y Fruta podrida (2007) claman por revertir las normas de un mundo que va perdiendo su humanidad a favor de la tecnología. Convertirse en aquel súper cíborg, propuesto por Donna Haraway en Simians, cyborgs and women (1991), que usaba la tecnología para erradicar la desigualdad, no parece posible en una ficción en la que la realidad dictatorial todavía hace estragos en la memoria. Los personajes sucumben ante su destino. Pero su mensaje todavía existe y resiste, y la monstruosa obra de Meruane advierte, recordando la identidad original del monstruo y sus habilidades videntes.

Palabras clave: Lina Meruane; monstruo; prehumano; manifiesto cyborg; cíborg; Haraway; Chile; tecnología; cuentos de hadas; enfermedad.

\section{[en] Prehuman monsters and super ciborgs in Lina Meruane's narrative}

\begin{abstract}
Chilean writer Lina Meruane's literary production penetrates the valley of monsters and searches every corner from where they could stalk. Aided by her characters, girls and adolescents, disobedient and in search of an identity which struggles not to be categorized, this essay analyses the representations of monsters in the work of the young writer. Fictional martyrs of a real world, the protagonists of Las infantas (1998) y Fruta podrida (2007) clamor for an inversion of the norms in a world which is losing its humanity in favor of technology. Becoming a cyborg, a creature who would use technology to eradicate inequality, as proposed by Donna Haraway in Simians, cyborgs and women (1991), does not seem possible in a fiction where the dictatorial reality still wreaks havoc with their memory. Characters succumb before their destiny. But their message still exists and resists, and Meruane's monstrous work still warns, recalling the monster's original identity and its psychic abilities.
\end{abstract}

Keywords: Lina Meruane; monster; prehuman; cyborg manifiesto; Haraway; Chile; technology; fairy tales; illness.

Sumario. 1. Introducción. 2. Las infantas, un trabajo de reinterpretación. 2.1. El monstruo prehumano. 2.2. El monstruo grotesco. 2.3. El monstruo sexual. 2.4. El supercíborg: tecnología textual. 3. Fruta podrida: una monstruosa máquina de desobedecer. 3.1. Entre la máquina y el

1 Deakin University, Victoria. Australia.

E-mail: alonsomirae@gmail.com 
monstruo, el poder y la desobediencia. 3.2. Disidencias enfermas. 3.3. Zoila, un cuerpo sin órganos. 4. Conclusión.

Cómo citar: Alonso Mira, E. (2019) Monstruos prehumanos y supercíborgs en la narrativa de Lina Meruane, en Anales de Literatura Hispanoamericana 48, 605-621.

Al lado de esto, el mundo es un pequeño jardín japonés, una bola donde baila una ventisca. Lo puedes esconder en el bolsillo de los pantalones y ser un monstruo de nuevo, vivir sencillamente de un hambre premonstruosa y devorar las piedras, la tierra, el cielo, las estrellas,

y seguir con apetito, aullar cuando los otros se duermen.

(“El perro de Orión” Tomasz Rózycki)

\section{Introducción}

Los veinte años durante los que Chile puso en suspenso las libertades de sus ciudadanos influyeron en el compromiso literario de la mayoría de escritores, intelectuales y artistas chilenos posteriores. La narrativa de Lina Meruane no ha eludido este viejo compromiso entre literatura y sociedad. Aunque joven, los años de represión, violencia y tortura han dejado una marca en su todavía breve obra. Junto a otras escritoras ${ }^{2}$ nacidas alrededor de los años setenta que comenzaron a publicar tras la vuelta de la democracia a Chile, como Andrea Maturana (1969), Nona Fernández (1971), Alejandra Costamagna (1970) y Andrea Jeftanovic (1970), Meruane comparte una revitalizada conciencia social que pretende dotar a la literatura, de nuevo, de su eternamente cuestionado compromiso, a través de propuestas que buscan plasmar la desesperanza social de un país que, en teoría marcha, pero que lo hace como un cuerpo traumatizado: sufriendo los efectos secundarios de una medicina económica que se aplicó sin haber sido testada. La protesta de Meruane se lleva a cabo a través de una serie de monstruos cuyo común denominador es su absoluto desprecio por un sistema social, cultural, político y económico que los limita y los controla. Principalmente, sus novelas presentan dos tipos de monstruos. Por un lado, el monstruo prehumano, es decir, aquella criatura

\footnotetext{
${ }^{2}$ Por sus similitudes con Diamela Eltit, escritora que empezó a publicar durante la dictadura y cuyos textos han sido criticados por su ilegibilidad y academicismo (Manzi s/n), a Lina Meruane se la calificó de "diamelita". Y aunque en sus inicios, esta denominación estuviera fuera de lugar, por el contexto en el que fue utilizada y por el matiz, más de menosprecio que de cariño que imprimía el sufijo diminutivo, hay definitivamente elementos de unión entre ambas escritoras, como la atención al cuerpo enfermo, particularmente al cuerpo femenino. Lina Meruane defendió su rechazo hacia este apodo explicando que aquella generalización se hizo desde la ignorancia del crítico Álvaro Bisama, que, sin haber leído a las autoras de las que hablaba, las encasillaba a todas bajo mismo nombre, retomando el apodo cariñosamente puesto por Bolaño e imponiéndole un nuevo significado: aquellas escritoras que creaban una literatura "para ser deglutida por la academia" (Rodríguez s/n)
} 
nacida entre hombres y mujeres que se quiere expulsar de la especie- porque se considera que pertenece a un estadio previo o inferior: a una especie peor que la humana, a la que podríamos denominar prehumana. Y, por otro lado, el supercíborg, térmido nacido del "Manifiesto cyborg" de Donna Haraway, cuya hibridez le permite superar todas las barreras que los seres humanos han creado para establecer diferencias. Los veremos en dos novelas, Las infantas y Fruta podrida. En Las infantas (1998), su primera novela, las protagonistas Hildegreta y Hildeblanca, servirán como ejemplos perfectos de una monstruosidad prehumana que se resiste a la normatividad de la civilización que las rodea; simultáneamente, las constantes metamorfosis experimentadas por sus personajes y la estructura de la obra que los contiene, mostrarán la hibridez de un texto que se vuelve monstruoso en su género. En Fruta podrida (2007), Zoila, enferma de diabetes, huye de la medicina en una aventura hasta su muerte, enfrentándose no solo a su hermana María, corporeización de la sociedad de mercado, sino a todo lo que ella representa. Así, expone la fuerza de un monstruo prehumano que se abraza a sus instintos y se niega a desaparecer, reclamando a través de su anormalidad un espacio de imperfección que cuestione la carrera hacia la comercialización de una imposible perfección humana.

\section{Las infantas: un trabajo de reinterpretación}

Las infantas $^{4}$ es el primer libro de cuentos de Lina Meruane. Está formado por dos textos diferentes que van alterándose, como dos libros que se intercalan. En los capítulos pares, se desarrolla la trama asociada a los cuentos de hadas y la magia constituye la esencia del género (Rabkin: 37). Los impares son relatos fantásticos, donde el mundo real se ve alterado por acontecimientos extraordinarios provenientes de los capítulos pares. La infección fantástica, provoca que los elementos de un lado caigan en el otro y que los personajes de un texto sufran las consecuencias de los actos del otro. Así, los relatos del primer texto funcionan

3 "Manifiesto cyborg" es el título del capítulo de Simians, cyborgs and women: The Reinvention of Nature (1991), que recibió más atención, por su lenguaje irónico y de llamada a la acción. Pero es la totalidad del ensayo la que lo dota de significado, ya que para llegar al manifiesto, a la llamada, primero Haraway toma como base de su investigación ensayos escritos desde 1978 hasta 1989 y deconstruye poco a poco las leyes de la ciencia que rigen el imaginario colectivo con el objetivo de reinterpretarla. ¿Es posible reinventar la naturaleza, reinterpretar todas sus teorías y leyes a través de los monstruos?, se pregunta Haraway al principio de su ensayo. Para ella los simios, las mujeres y, recientemente, los cíborgs han compartido un espacio similar en las narrativas evolutivas, tecnológicas y biológicas de la sociedad occidental. Todos ellos han sido presentados como monstruos. Las posibilidades que ofrece la figura del cyborg, el último en aparecer, es capaz de unirlos a todos y ofrecerles una nueva versión de sí mismos.

${ }^{4}$ Para las citas, se ha utilizado la primera edición de Las infantas, impresa en Buenos Aires en 2010 por Eterna Cadencia. 
como un reflejo del mundo de la fantasía en el mundo real. Los actos de un tiempo pretérito, el tiempo de los cuentos de hadas, cobran sus deudas en las miserables vidas de un tiempo presente. Así, cada relato del primer texto introduce nuevos personajes y situaciones que no terminan de resolverse, pero que mantienen elementos alterados del resto de ficciones. Este contagio sugiere que ninguna lectura es inocente; el mundo de la fantasía acaba por introducirse en la realidad y tiene el poder de alterarla. La intención de las Las infantas es precisamente atentar contra el sentido de la normatividad impuesta. Lo hace, por un lado, a través de los personajes, y por otro, a través del texto: los personajes alteran la normatividad mediante sus "perversiones sexuales", que van desde el incesto hasta la pederastia, pasando por la necrofilia; el texto, mediante las transmutaciones y metamorfosis que provocan que los personajes vean su identidad arrebatada, fragmentada y entregada a algún otro personaje, en algún otro capítulo.

Lina Meruane no es la primera escritora que decide intervenir los cuentos de hadas para reinterpretarlos a su antojo. Unos años antes de Meruane, Luisa Valenzuela incluía en su libro Simetrías $(1993)^{5}$, "Cuentos de hades", relato que jugaba a colocar los motivos, los temas y los personajes de los cuentos de Perrault en situaciones diferentes para invertir los códigos socioculturales en los que se basaban. Para Valenzuela, el objetivo principal era "devolver los cuentos más clásicos de Perrault no a su tiempo, pero sí a lo que pienso fue la intención original de las viejas narradoras orales. Ejemplos de libertad mejor que llamados al sometimiento" (Valenzuela 2002: 190). En la misma línea, Meruane, además de modificar el modelo de conducta femenino para ampliarlo y dotarlo de más libertad, trata de alterar todos los modelos y estructuras, tanto culturales como textuales. Por eso, intercala escenarios pertenecientes al mundo de la fantasía, en los que la magia constituye la esencia del género, con relatos fantásticos al estilo cortazariano ${ }^{6}$, donde los eventos de un mundo "real" se ven interrumpidos por acontecimientos extraordinarios.

Al igual que Perrault ${ }^{7}$, que recopiló y modificó las historias folclóricas en Histoires ou contes du temps passé (1967), aprovechándose de la magia natural del género que permite; primero, la naturalización de eventos imposibles, y segundo, la traducción por parte del lector de estos eventos a su realidad psicosocial (Bacchilega 29), Meruane recopila fragmentos de Perrault y los hermanos Grimm y

${ }^{5}$ La colección Simetrías, publicada por primera vez en 1993, está incluida dentro del volumen Cuentos completos y uno más (1999).

6 "Casi todos los cuentos que he escrito pertenecen al género llamado fantástico por falta de mejor nombre" afirmaba Cortázar en referencia a su estilo en "Algunos aspectos del cuento"

${ }^{7}$ Los hermanos Grimm hicieron lo mismo, aunque hubo divergencias entre los hermanos. Mientras que Jacob Grimm perseguía un objetivo puramente filológico y pretendía principalmente recopilar las historias originales, interviniendo lo menos posible, Wilhelm Grimm fue, versión tras versión, modificándolos cada vez más, para hacerlos más infantiles, eliminando la mayoría de alusiones sexuales, pero manteniendo casi todos los actos violentos. 
modifica su función didáctica, naturalizando comportamientos previamente censurados. En primer lugar, Meruane devuelve a las mujeres su papel activo, tanto en la creación de sus historias -es ella la escritora-, como en la aplicación de sus leyes - son las hermanas Hildegreta y Hildeblanca las que acaban por imponer una normalidad que van creando en función de los eventos a los que se enfrentan. En segundo lugar, al hacer protagonistas de su catálogo de perversiones sexuales a dos niñas, cubre, por un lado, con un halo de inocencia cualquier actuación que inicialmente podría parecer perturbadora, y por otro, naturaliza estos comportamientos, de manera que actuaciones que inicialmente pudieran resultar prehumanas -como la afición de las hermanas por olfatear su ropa interior-, acaben por parecer naturales hacia el final del texto ${ }^{8}$. Así, el lugar "periférico", "desventajado" o "subalterno" de la niñez se utiliza precisamente para plasmar una resistencia, revertir el lenguaje y las tiranías ideológicas y generar una alternativa al saber estipulado a través de las subjetividades particulares de la infancia (Osorio $\mathrm{s} / \mathrm{n}$ ). Y, por último, Meruane vuelve a aproximarse a los cuentos folclóricos al naturalizar eventos como el incesto o el embarazo no deseado, ya presentes en las versiones orales (Tatar: 11). No obstante, mientras que los actos sexuales "anormales" se libran de toda penalización y, a través de su repetición, adquieren su estatus de normalidad, otras rupturas de la ley, como el asesinato, sí acaban por ser juzgadas y castigadas.

\subsection{El monstruo prehumano}

Como en todo cuento, siempre tiene que haber un monstruo y en este caso el monstruo es imprescindible, porque es el encargado de franquear los límites establecidos por los relatos previos que Meruane trata de desmontar. De acuerdo con el Diccionario crítico etimológico castellano e hispánico (1981) de Juan Corominas, "mōnstrum" en latín significa "hecho prodigioso o advertencia de los dioses", significado proveniente de "mōnstrāre" que significa "mostrar, indicar, advertir". Es posible que monstrare fuera derivado indirecto de mōnere. En cualquier

${ }^{8}$ El niño o la niña tiene la capacidad de ocupar un lugar subalterno casi monstruoso en cuanto que 1) provoca sorpresa y escándalo en el adulto, por llevar a cabo acciones que se encuentran fuera de la civilización 2) es un interrogante hacia el futuro, un "significante abierto" a través del cual se abre una posibilidad al cambio 3) permite, como personaje, la transformación de su vulnerabilidad en arma, si de él se espera inocencia, el mensaje entra despacio, pero llega, porque la niñez es capaz de decir todo lo que sabe, pero sobre todo de imaginar lo que no sabe, por lo que es capaz de crear, a través de su ignorancia, un universo libre de estructuras (Jeftanovic: 13-14).

${ }^{9}$ La subalternidad ha sido estudiada desde distintas perspectivas que giran en torno a un poder que pasa de mano en mano, pero que no llega a la periferia, por eso Nelson Osorio se refiere a él como "sujeto periférico" porque para él incluye todo lo que no forma parte de las categorías dominantes (mujeres, homosexuales, niños...), no solo aquellos considerados marginados sociales (Osorio $\mathrm{s} / \mathrm{n}$ ). El sujeto subalterno es, de acuerdo con Gayatri Spivak, el otro sujeto, un sujeto marginal cuya situación liminal queda al margen del poder económico y político, un sujeto cuya voz es sustituida, "hablada" desde el centro. 
caso, a lo largo de su historia, el monstruo se ha utilizado para señalar todo aquello que resulta diferente, desconocido y, por lo tanto, temido, por lo que pragmáticamente, casi todas sus acepciones se usan como insultos: desde el bárbaro extranjero al enfermo moribundo, del indígena al homosexual, de la mujer al anciano. Esto es así porque el monstruo muestra aquello que se encuentra más allá de unos límites que nunca deben ser franqueados, por eso, en función de las necesidades del momento, a lo largo de la historia, el monstruo, que hemos denominado aquí prehumano, ha ido adquiriendo diversos papeles. Aparece en Las infantas como a) monstruo vidente a través de la presencia de las plagas, b) monstruo extranjero que incurre en comportamientos no normativos, c) monstruo grotesco que expone sin vergüenza sus fluidos más íntimos, d) monstruo erótico cuya excesiva sexualidad exige desobediencia, o e) el monstruo femenino, actualizador de Medea en su papel de infanticida. Veamos con más detenimiento algunos de ellos.

\subsection{El monstruo grotesco}

Afirmaba Bakhtin que "the grotesque body is not separated from the rest of the world. It is not a closed, complete unit; it is unfinished, outgrows itself, transgresses its own limits as the apertures of the body, the open mouth, the genital organs, the breasts, the phallus, emit fluids that flow in and out, to and from other bodies" (Edwards y Graulund: 24).

Los cuerpos de Las infantas cumplen con todas las características de un cuerpo grotesco y lo hacen a través de una humedad que salpica todos los elementos del relato. Las noches son húmedas (43), igual que lo es el "piso" (94) y el parqué con sus "trozos húmedos de madera" (113), así como las manos $(45,67)$ y los cuerpos sudados $(49,58,65,74,93,107)$ o brillantes "como si estuviera cubierta de barniz" (50), que en ocasiones alcanzan otros cuerpos: "un líquido descendía entre sus pechos. Me salpicaba en cada golpe" (51), "sus pies desnudos se adhieren al piso plástico y se despegan como ventosas" (81), "si se empapa tardaría demasiado en secarse" (94).

Igualmente, se insiste pleonásticamente en la humedad de las lenguas calientes $(13,15,21)$ y los labios: "Bostezó sin taparse la boca para luego mojar su labio inferior con el meñique ensalivado" (32). Las manos, en vez de tocarse, "se soban" (63). Las caricias aceitosas (38), a veces se contagian de la humedad y otras se vuelven "ásperas" (51). Los lamidos se multiplican: "me olisca entre las piernas y me lame el cuello" (44) y la saliva se usa en unas historias para hacer "correr las páginas [...] en un espasmo" (45) o en otras para aplicarla a "una hoja de acanto para acariciarse con ella entre los muslos" (52), pero también para predecir la llegada de comida: "salivaba copiosamente pensando en la cena" (57), "cruzó la calle salivando ante la idea de conseguir bolitas de chocolate" (88), "revienta ruidosamente un globo de chicle esparciendo un aroma a menta y saliva" (79); o incluso para hablar del fuego: "las llamas me iban cercando, iban salpicándome de ardiente saliva" (70). A veces, esta saliva se convierte en "baba blanquecina" (52), que prevé la llegada del semen. También aparece a través de los lamidos: "El pequeño animal estaba cubierto de barro seco. Greta escupió sobre él para limpiarlo, le lamió la tierra y las hojas adheridas al pelaje agrietado" (35), "Miguel le estaba pasando la lengua al plato" (61). Pero no solo la saliva se contagia, sino 
que las lágrimas también saltan de un cuerpo a otro: "al apretar mi boca contra la punta de sus pezones para empaparme con su fastidioso lamento por la madre muerta" (67).

Otros fluidos indeterminados también se extienden por el relato mojando los cuerpos: "un fluido viscoso chorreó de mi nariz" (53), "quedan los fragmentos de las cápsulas, su relleno blanco y amargo" (83), "sintió [...] un roce de algo palpitante, mojado pero compacto como nieve fuera de estación" (89), "Lo escucho caer pesadamente sobre la escalinata que da a la puerta; resbala desmembrándose sobre el cemento" (91).

A veces, la humedad prevalece a través de un olor a tierra mojada, que desliza de relato en relato, pero otras "la hediondez proveniente de los cubos" (50) que esperan su descomposición invade los sentidos. $\mathrm{Y}$ a veces, los fluidos cambian de color, del blanco del placer, al rojo del dolor, cuando aparece la sangre: "me ardía la lengua, los fierritos me habían herido los labios por dentro y todavía me sangraban las encías" (27), "sintió la sangre agolpándose en sus mejillas" (61), "se limitó a secar la sangre del hacha con una servilletita de papel" (74). Otras veces, son los cuerpos mutilados o heridos los que indican su presencia ausente: "Y se miró la uña del meñique, larga, pintada burdeos. La enterró en el cordón y saltó un chorro oscuro, un espeso fluido, que ella limpió con la lengua, pensando que sabía a metal" (34), "Lo puso entre sus labios y volvió a succionar ese fluido salobre, plasmático" (35), "el mendigo asintió e introdujo sus dedos en los extremos de su boca, comenzó a estirar la piel de los labios, a ensanchar la boca para mostrarle las encías: un hueso ralo y herido (101), "la vieja, mutilada. La de la nariz chueca. Cortada, la lengua..." (75) hasta su llegada "Sangre. Sangre. Sangre por todas partes" (76). Pero la humedad también puede aparecer precisamente por su ausencia: Blanca sueña con "un vasito de agua" (44), "agüita ácida, algo dulzona" (45) que no puede conseguir. A la "vieja rata" también le es negado: "tengo sed, pero no me da de beber" (80).

A través de estos numerosos ejemplos y otros más presentes en el texto que hacen referencia directa a todo tipo de fluidos que transgreden sus propios límites, para saltar de un cuerpo a otro y atravesar todo el texto, podemos afirmar que no hay duda alguna de que el monstruo grotesco encuentra un espacio en el relato. Estos fluidos apelan a despertar los órganos sensoriales del lector con objeto de obtener una respuesta directa, ya de rechazo, ya de aceptación. Su presencia excesiva consigue normalizarlos, la repetitiva transgresión de los límites del "buen gusto" consigue normalizar su presencia, y llegar a la revelación de que todos los cuerpos son grotescos, en algún momento u otro.

\subsection{El monstruo sexual}

La constante presencia a la humedad, no obstante, también ofrece otra posible lectura que permite la aparición del monstruo erótico. La humedad está ligada al deseo femenino y su constante presencia indica que ese deseo viscoso escapa capítulo a capítulo, en busca de una satisfacción que nunca encuentra. La ausencia constante de satisfacción plena alimenta un deseo que no cesa y que mantiene al monstruo erótico con vida. Este monstruo prehumano usa el erotismo como principal recurso transgresor. Recordemos que Bataille, tras destacar en su célebre 
L'Erotisme (1957) la estrecha relación existente entre el erotismo y la violencia, comenzó a usar el erotismo como estandarte de la desobediencia. Por su parte, la investigadora Mónica Ojeda sugiere a través de lo que denomina escritura pornoerótica $^{10}$, es decir, "aquella que baila entre lo erótico y lo pornográfico" (60) que la escritura pornográfica, erótica o la combinación de ambas, se ha usado en Latinoamérica para crear una narración cuya irreverencia fomenta la rebeldía.

Así, en Las infantas, Meruane enarbola y agita la bandera pornoerótica, fracturando toda normatividad, no porque pretenda aprobar o normalizar ciertas conductas sexuales, sino para reflexionar sobre el origen y el sentido de ciertos patrones establecidos. Así, su discurso va más allá de ampliar y validar el catálogo de sexualidades: por un lado, pone de manifiesto la enorme variedad de subjetividades individuales que no encuentran en la sociedad un espacio de expresión y, por otro, extrapola una desobediencia inicialmente sexual al resto de ámbitos.

El recurso a un erotismo que en ocasiones roza lo pornográfico no es exclusivo de Meruane. La escritura pornoerótica tuvo un auge en los años ochenta del siglo XX con escritoras como Armonía Somers, Reina Roffé Susana Constante, Liliana Heer, Ana María Shua, Silvia Molloy, Cristina Peri Rossi, Griselda Gambaro, Alicia Steimberg o Tununa Mercado. "Si la obscenidad había sido tradicionalmente empleada para degradar y humillar a la mujer [...] debería ser doblemente efectiva para redimirla" (148), se decía Rosario Ferré en en La sartén por el mango (1985). Así, frente a una vigilancia ciudadana que trabajaba, a través de la novela naturalista, en la construcción de los imaginarios nacionales, insertando el temor a lo monstruoso como consecuencia de las "perversiones patológicas del deseo" (Nouzeilles: 84) ${ }^{11}$. Meruane sigue el camino de sus predecesoras a través de un "exceso de sexualidad" para fomentar una descategorización tanto del deseo como del resto de expresiones humanas.

\subsection{El supercíborg: tecnología textual}

Los relatos de Las infantas son en palabras del investigador chileno Daniel Noemi Voionmaa "historias simbólicamente destinadas a una infancia (tiempo pretérito) que se actualizan en un presente que asume y reconoce lo más horroroso de ese pasado que regresa macabro (70). Es decir, reclaman una revisión de la historia cuyas repercusiones presentes deben ser revisadas y volteadas. En este sentido, es posible considerar la postura de Lina Meruane paralela a la de Donna Haraway y su

\footnotetext{
${ }^{10}$ Véase el artículo "Pornoerótica latinoamericana: subversión en la narrativa de mujeres en el exilio" de Mónica Ojeda Franco.

11 Gabriela Nouzeilles afirma en Ficciones somáticas: naturalismo, nacionalismo y políticas médicas del cuerpo (Argentina 1880-1910) que "a la hora de producir ficciones somáticas de la identidad, naturalismo, nacionalismo y medicina se complementaron. En todos los casos, el exceso de sexualidad fue visto como inhumano, patológico e inherentemente antisocial" (23). Aunque su estudio está centrado en Argentina, la autora extiende la influencia de estas ficciones patológicas al resto del Cono Sur.
} 
revisión historicista de la ciencia. En Simians, Cyborgs And Women: The Reinvention Of Nature (1991), Haraway se preguntaba de forma optimista si habría otra forma de significación, otra forma de traducir y reinterpretar la naturaleza históricamente contingente del simio, el cíborg y la mujer, e imaginar un mundo donde un ser híbrido apostaría por la supervivencia y la igualdad. Este ser no debía ser ni dios ni humano ni máquina, sino una combinación de todo lo anterior. Además, debía carecer de familia y de pasado propio y su único horizonte y objetivo era acabar con la desigualdad, utilizando como arma la tecnología. No obstante, el supercíborg va más allá de su forma, no necesita ser un organismo cibernético, pero sí un ser de la época por venir. En palabras de Haraway, el cyborg es:

a hybrid creature, composed of organism and machine. But cyborgs are post Second World War hybrid entities made of, first, ourselves and other organic creatures in our unchosen 'high-technological' guise as information systems, texts, and ergonomically controlled laboring, desiring, and reproducing systems. The second essential ingredient in cyborgs is machines in their guise, also, as communication systems, texts, and self-acting, ergonomically, designed apparatuses (Haraway: 1)

En este caso, y dado que Las infantas se encuentran insertas en un relato donde la magia es posible, la tecnología es sustituida por la magia propia del género, pero la propuesta sigue siendo la misma. En primer lugar, los personajes de Meruane superan todas las limitaciones humanas, orgánicas y físicas: los nombres y los arquetipos de Perrault se fusionan y reinterpretan de forma que los cuerpos de Hildeblanca y Hildegreta se abren y multiplican; se convierten en reinas de picas en niñas introvertidas, en muñecas metálicas, en bailarinas, en artistas y un largo etcétera. En segundo lugar, las infantas renuncian a su familia y a su reino, estructuras sociales ambas asociadas a un sistema sociocultural patriarcal, y comienzan su nueva vida a partir de una identidad vacía que pueden empezar a diseñar a su antojo. En tercer lugar, al igual que el supercíborg, Hildeblanca, Hildegreta y la miríada de personajes que orbitan a su alrededor fusionándose con ellas, reinterpretan las asunciones del pasado para crear un futuro más igualitario. $\mathrm{Y}$ este es precisamente el punto más problemático en la construcción del supercíborg. Hildeblanca y Hildegreta carecen de memoria. Ambas la han perdido, es el acuerdo al que llegan desde un principio para salvarse de un destino impuesto en el cual no iban a ser más que mercancías. No obstante, la memoria de un pasado, que pertenece a una realidad inalcanzable para ellas, una realidad extratextual, las acecha a través de la mención de los cuerpos torturados y desaparecidos de la dictadura chilena. La ficción y la posibilidad de vivir en un cuento de hadas donde pueden ejercer la magia a su antojo no las libera del horror del espacio en el que la realidad del texto se hará pública: Chile. El supercíborg fracasa en su batalla contra una memoria que se empeña en dejar marcas para indicar aquello que no se debe repetir. Por eso, el homicidio es el único delito que exige ser pagado. 


\section{Fruta prohibida: disidencias monstruosas}

Fruta podrida (2007), novela ganadora del Premio a la Mejor Novela Inédita en el 2006 por el Consejo Nacional de la Cultura y las Artes en Chile, está construida alrededor de de la enfermedad de su protagonista, Zoila, y de su hermana María. María, ingeniera agrónoma, ha convertido su vida en la constante persecución y erradicación de plagas y enfermedades, tanto de las frutas que tiene a su cargo en la empresa de exportación frutícola, como de su medio hermana pequeña. Zoila, enferma de diabetes y de desobediencia, "enfermedad congénita, también irremediable" (70), se opone abiertamente a esta empresa de salvación y sabotea desde el principio cualquier intento de rescate, aunque nadie entienda que se "niegue a la inmortalidad, que prefiera una libertad de corto plazo" (70).

\subsection{Entre la máquina y el monstruo, el poder y la desobediencia}

La narración oscila principalmente entre dos espacios, Ojo Seco, el cobertizo donde viven, y el Hospital. Ambos actúan como espacios clínicos de higienización y por lo tanto, espacios clave de renegociación política, donde se intensifican las relaciones tanto corporales como tecnológicas. (Haraway: 172). En el hospital, el "Médico", prototipo de científico obsesionado únicamente con su ciencia, es el encargado de incorporar a Zoila y a María al sistema hospitalario, de forma que, al convertirlas en productos humanos, consiga aumentar su productividad. Así, el Médico convence a María de que haga de su propio útero un espacio de creación de órganos lo suficientemente eficiente como pagar el tratamiento de su hermana. De esta manera, María, madre soltera, se convierte en la madre del sufrimiento de al menos una decena de criaturas que irán a parar al mercado de la experimentación científica, erigiéndose, no como una virgen santa, sino como una Medea contemporánea que no asesina a su progenie por venganza, sino que dona una decena de vidas a cambio de un tratamiento que no es más que una promesa. En este sentido, María es un monstruo prehumano, capaz de asesinar a unos por la supervivencia de los otros. Su inhumanidad radica en la presunción de que sus donaciones no son más que productos engendrados para la venta. Por eso, la visión de los órganos no se expone en términos vitales, sino en términos económicos y mecanicistas:

Y la Mayor observaba ese diagrama del cuerpo imaginando una sofisticada planta procesadora provista de esfinteres de entrada y salida, de intestinos distribuidores, de fajas transportadoras y de arterias. En cada punto, pensó la Mayor examinando la anatomía, había químicos, ácidos y un elaborado sistema que destruía los gérmenes, había almacenes y oficinas donde se elaboraban las estrategias de producción. Una máquina perfecta (23).

Al establecer este paralelismo entre cuerpo y máquina, Meruane denuncia que, a partir de la modernidad, no solo se continúa insistiendo en la división cartesiana entre mente y cuerpo, sino que se ha llegado más allá. En vez de comparar la máquina cuerpo, "se compara el cuerpo a la máquina" (Breton: 203). 
Por su parte, el Médico parece haber interiorizado esta mecanicidad deshumanizada en su carrera contra la precariedad del cuerpo humano: "La Mayor siguió los ojos metálicos del Médico, ahora fijos en su panza" (29). Por eso, asegura un futuro prometedor que abolirá la muerte, aunque tenga que intercambiar vidas a cambio de las herramientas necesarias: "sobre mi cadáver se morirá alguien en este hospital. Para qué cree que estamos trayendo tanta máquina, tanta tecnología importada contra la muerte" (23). El Médico convence a María y la contagia de una alegría robótica dirigida por un objetivo deshumanizado verdaderamente monstruoso: el del progreso a cambio de la vida de todos los bebés que ella deberá tener y donar a la ciencia, pero aun así "ella también sonrió, sin saber por qué le concedía impúdicamente los labios despegados y los dientes: era una mueca mimética y automática que resplandecía" (29).

Zoila, por otro lado, es el animal instintivo, el monstruo prehumano, que se niega a abrazar el destino que ya su nombre tenía preparado para ella: Zoe Leyland, cuya fonética en español se aproxima a Zoila, fue el nombre dado a la primera niña probeta en 1984. En el texto de Meruane, sin embargo, Zoila se niega a convertirse en un producto de la ciencia y abraza su animalidad. Así se refiere a ella el narrador inicial, como a un "bicho recién fumigado" (15). Desde el principio, Zoila pierde simultáneamente su humanidad y la propiedad de su cuerpo, que pasa a ser "el cuerpo de Zoila pero sin Zoila" (19), es decir un cuerpo anónimo que tras enfermar ha perdido su identidad, quedando convertido en "la disposición en engranajes de un organismo percibido como una colección de órganos y de funciones potencialmente sustituibles" (Le Breton: 198). Pero, también desde el principio, Zoila rechaza tajantemente el destino que asociaron con su nombre a esa identidad, ahora difuminada, un destino que la enfrenta a su propio cuerpo, convirtiéndola en borrador de una máquina perfecta que quizás nunca exista. Zoila se opone a la historia, una historia de técnica y ciencia, de correcciones del cuerpo bajo la que subyace un fantasma, una idea aterradora y atrayente, una idea monstruosa, la de "abolir el cuerpo" (Le Breton: 202) para sustituirlo por una máquina capaz de evitar la muerte, porque "la muerte era contraria a la ética médica" (Meruane: 62).

Pero la muerte es el destino final. Así lo entiende Zoila y es así también como decide reescribir ella su destino a través de su cuaderno de "deScomposición", un cuaderno en el que su cuerpo encuentra su lenguaje y se enfrenta al que debe ocupar esas páginas: controles de todo aquello que come y no come, cantidades y cifras que deberá mostrar a su hermana y los médicos. Zoila escribe su cuaderno con su cuerpo. Pero Zoila no solo escribe con su cuerpo desde una perspectiva femenina basada en un deseo plural alejado de "la economía fálica dominante" (2009: 17), como proponía Irigaray en Ese sexo que no es uno. Si Irigaray sugería que la mujer debía encontrar un sistema representativo propio para definirse de acuerdo a una identidad alejada de la creada para ellas por los hombres (2009: 59), Zoila busca un lenguaje disidente, agenérico y humanizador que se aleje de una vida de esclavitud médica y descubre en la perspectiva de la muerte el placer de una vida suicida.

Así, escribe: "vendrán los tiempos en que/también/me descuelgue del mundo/cubierta de hongos/repleta de gusanos para rodar/ quién sabe por qué caminos/tiñendo la tierra/ magullando mi piel hasta pelarla" (33). A través de este 
poema, Zoila se animaliza y escribe invocando a la muerte, como destino vital, ya no de todo ser humano, sino de todo ser orgánico. Así, reclama su lugar como parte de una cadena y disfruta en el camino de una humanidad podrida, embarrada y sucia, antagonista de la obsesión higienista preponderante. El deseo, no de desaparecer, sino de hacerlo lentamente, dejando que la enfermedad continúe su curso natural, se repite varias veces a lo largo del relato: "y yo imagino que me infiltro, gangrenada, en esa tierra suya siempre prometida" (74), "la enfermedad es mía, no dejaré que me la quiten" (78), insistiendo en la naturaleza de una enfermedad que no debe ser estigmatizada, sino formar parte del curso natural de la vida.

\subsection{Disidencias enfermas}

Meruane no solo recuerda a través del comportamiento aparentemente irracional de Zoila que la enfermedad es inevitable y la muerte parte de la vida, sino que utiliza la enfermedad como estrategia disidente. Zoila no quiere estar enferma porque le gusten las limitaciones de su enfermedad o porque disfrute con el sufrimiento que lleva asociado, sino porque la alternativa es someterse al control ajeno. Su enfermedad es la alarma y el arma que tiene para atacar al sistema que pretende erradicarla. La resistencia de Zoila a su tratamiento, se puede leer en tres niveles diferentes: sanitario, socioeconómico y político.

En primer lugar, Zoila entiende su humanidad como un pulso del propio cuerpo contra el ambiente en el que está inserto. Por un lado, necesita llevar a cabo su propia lucha para salir adelante y entender, según avanza su enfermedad, los distintos procesos corporales por los que debe pasar todo ser humano en su transición desde la vida hasta la muerte. Zoila elige sentir la putrefacción y vivir en los extremos del placer y el dolor, en vez de continuar por la senda del miedo. Pero, por otro lado, también rechaza el entorno que la ha hecho enfermar. Es posible que Meruane eligiera la diabetes porque ella misma la sufrió, pero también porque la diabetes es una enfermedad cuyo incremento se debe a un cambio de dieta y de estilo de vida resultado de un progreso que convierte en víctimas a los más desfavorecidos (Anderson et al.: 2016). En general, es una enfermedad que ha ido incrementando sus víctimas a nivel global, a medida que los distintos países han ido alcanzando mayores niveles de desigualdad. Por eso, para Zoila, el tratamiento no se debe centrar en ella, sino que debe ampliarse a toda la sociedad, no solo chilena, sino global. El tratamiento no debe únicamente aliviar los síntomas, provocando enfermedades yatrogénicas ${ }^{12}$, sino atajar las causas.

En este punto, merece la pena recordar el concepto de némesis médica que proponía Ivan Ilich (1975). Illich utilizaba el concepto de némesis griega, es decir, la representación de la venganza divina que los mortales debían sufrir cuando intentaban usurparles los privilegios a los dioses. Némesis era el castigo a los

\footnotetext{
12 Yatrogénesis: palabra formada por yatros (médicos) y génesis (origen), se refiere a aquellas enfermedades que surgen debido a la intervención médica (Ivan Ilich 23). Bajo esta definición, Ivan Illich también entiende que todos los remedios, médicos y hospitales pueden convertirse en los agentes principales causantes de la enfermedad.
} 
intentos de inhumanidad perpetrados por el ser humano, la respuesta natural de la naturaleza a la arrogancia humana. Para Illich, "nuestra hubris higiénica contemporánea ha conducido al nuevo síndrome de Némesis médica" (Illich: 31). En el caso de Fruta podrida, la némesis médica se extiende y alcanza todos los procesos vitales. El Médico y la Mayor no se limitan a intentar frenar la enfermedad del cuerpo humano, sino que pretenden "curar" la naturaleza, a través del tratamiento continuo de los alimentos: "los hongos ocultos bajo la corteza de los troncos. Las malezas que estrangulan las raíces de los árboles. Los guarenes nadadores de los canales de regadío. Todos deben ser destruidos por ella para que le fruta engorde" (69). Estos tratamientos que alteran la fruta, ofreciendo imágenes plásticas, pasan a formar parte de un círculo vicioso que activa la enfermedad de Zoila, cuya alimentación incluye grandes cantidades de frutas y mermeladas repletas de azúcares. La "némesis médica es resistente a la atención médica. Solo podrá invertirse su acción cuando el profano recupere la autoasistencia mutua y el reconocimiento jurídico, político e institucional de ese derecho a atenderse" (32), afirmaba Illich. Y eso es precisamente lo que busca Zoila cuando se libera de todo tratamiento y decide dejarse morir mientras elabora su plan de acción para liberar a aquellos que, entubados, han perdido la capacidad de decisión. Por otro lado, aparece una nueva especie de la mosca de la fruta que empieza a arrasar todas las plantaciones, la drosophila melanogaster, una mosca cosmopolita que "inserta sus larvas dentro de manzanas, ciruelas, uvas que la nutren" (68) y viaja en "la mercancía de exportación y en el postre de los turistas" (68). Una mosca, por tanto, que se ha convertido en problema a causa del propio sistema de importación y exportación de fruta; otra plaga yatrogénica.

En este sentido, Meruane presenta la enfermedad como resistencia contra un sistema cuyas políticas socioeconómicas contribuyen al sabotaje de la salud física y mental de sus propios ciudadanos. Por eso, Meruane utiliza un lenguaje de guerra, común entre los distintos discursos políticos y que remite directamente al golpe de Estado del General Pinochet: "lo que ha atentado contra su hermana es su propio sistema defensivo, conjeturó el Médico, es como si ese sistema hubiera sufrido un lapsus, un trastorno, un golpe de Estado, y en su paroxismo se hubiera dedicado a aniquilar las propias células que lo mantienen vivo" (25). Es fácil ver la alegoría del cuerpo enfermo como el cuerpo estatal que sufre ante la actuación de su propio ejército defensivo al levantarse contra ellos. Zoila no acepta una cura que convertirá su cuerpo y el de su hermana en esclavos perpetuos del hospital y, como extensión, de los distribuidores del norte. El rechazo al tratamiento prescrito, diseñado en el norte, al igual que la cura económica de Chile, funciona como llamamiento de resistencia ante las políticas económicas impuestas durante el régimen dictatorial y reforzadas tras el fin de la dictadura.

Así, desde una perspectiva económica, Zoila ignora el tratamiento del médico, en un claro rechazo alegórico al tratamiento económico impuesto a Chile y diseñado por los Chicago Boys ${ }^{13}$. Zoila desea la propia descomposición de su

${ }^{13}$ Se conoce como Chicago boys al grupo de economistas chilenos que realizaron sus estudios de posgrado en la Universidad de Chicago bajo la influencia de Milton Friedman y participaron en el derrocamiento del gobierno de Salvador Allende (Cárcamo-Huechante: 2006). 
cuerpo en un llamado hacia la descomposición de un sistema que no ha sido diseñado por y para sus ciudadanos. El exceso de medicación en los cuerpos y de pesticidas en los alimentos tienen como consecuencias: a) la dependencia de las cada vez menos numerosas multinacionales controladoras de semillas resistentes a los pesticidas, b) la progresiva resistencia de cuerpos y plantas a los distintos medicamentos y pesticidas que aumenta la propagación de enfermedades yatrogénicas. Así, la resistencia de Zoila es firme y constante. Por eso, a medida que pasa el tiempo, deja de limitarse a ella misma y se extiende al resto de la sociedad, culminando con el atentado de Zoila al hospital.

Por último, Zoila resiste de forma política. Su desobediencia se enfrenta a los sistemas de control establecidos: tanto el hospital como Ojo Seco se erigen como espacios de disciplinamiento ante los que debe personarse para demostrar, a través de los análisis, que sus hábitos alimenticios han sido modificados de acuerdo con la normativa establecida para su caso. El Médico es el dictador, juez y legislador, encargado de emitir las normas y asegurarse de que se cumplan, a través de las fuerzas del orden, en este caso el enfermero y su hermana. No obstante, es un dictador subyugado por poderes extranjeros, que obedece normas que "dictaron científicos extranjeros" (40). De la misma manera, el dueño y señor de Ojo Seco es el padre de Zoila, extranjero y ausente, que aparece una sola vez para recordarle a la Mayor los compromisos adquiridos. El poder, siempre extranjero, ha conseguido diseñar una sociedad de control en la que los propios ciudadanos ejercen de vigilantes de sí mismos y de los demás, como ya sugería Foucault (2000). Zoila, sin embargo, parece no formar parte de ella; todavía en la fase de disciplinamiento, es decir, instruida y controlada por las instituciones, pero sin haber interiorizado sus enseñanzas, se sirve de la sabiduría de sus instintos para aguantar. Su resistencia expande sus extremidades en todas direcciones. Su cuerpo y su comportamiento colaboran para impedir el avance de la ciencia. Su enfermedad evoluciona y se agrava; sus análisis, debido a sus trucos y engaños, parecen, durante un tiempo, perfectos. Su plan, cuidadosamente diseñado, funciona, e incursión tras incursión va "salvando" de una vida dependiente a enfermos como ella.

Otros cuerpos femeninos la ayudan en su obra. Las temporeras de Ojo Seco comienzan a menstruar todas simultáneamente "misteriosamente sincronizadas por las hormonas" (90), lo que las obliga a detener su trabajo para ir al baño constantemente. Ante la amenaza de descontarles sueldo por cada minuto que pasaran en el baño, las temporeras se ponen en huelga. Pero, en vez de unirse a ellas como mujer y entender sus reclamos (pago de horas extraordinarias, aumento de sueldo acorde con el incremento de productividad, etc.), María consigue dividirlas y despide a las dirigentes.

Tanto Zoila como las temporeras, a través de sus cuerpos y sus acciones, dan forma al monstruo prehumano. Sus misteriosos e incomprensibles comportamientos destruyen una calma, una paz y una normalidad con las que no se encuentran cómodas, atentando contra un sistema que les obliga a desatender sus 
propios cuerpos, representantes de un conocimiento instintivo que se encuentra más allá del propio entendimiento.

\subsection{Zoila, un cuerpo sin órganos}

En 1973, Deleuze y Guattari publicaron El antiedipo: capitalismo y esquizofrenia. El objetivo principal de este trabajo era deconstruir la idea del complejo de Edipo propuesta por Freud, ilustrando que no era posible analizar sistemas complejos a través de una única variable. El ser humano era un sistema complejo: una máquina compuesta por una serie de deseos que se alimentaban unos de otros eternamente. En esta constante producción de deseos, este ser-máquina-deseante producía a la vez múltiples identidades que se acoplaban a sus deseos en un círculo infinito que solo podía terminar en un estado esquizofrénico -en el cual el ser dejaría de preguntarse sobre su "yo" porque el "yo" habría dejado de ser relevante -, o mediante la muerte. Una de las imágenes propuestas por Deleuze y Guattari es la del hombre sin órganos. Si el hombre no puede parar de producir, porque cada una de sus partes-órganos tienen deseos diferentes, la única forma de parar la inercia es vaciar el cuerpo de sus deseos, o - a través de una reinterpretación del texto de Artaud, Van Gogh: le suicide de la societé- vaciar el cuerpo de sus órganos "because the organs of life are the working machine" (Deleuze and Guattari: 8). El cuerpo sin órganos de Deleuze representa un cuerpo desmecanizado y vacío de deseos. Así, puede entenderse como una reacción a la repulsión de producción: una metáfora de un yo deshabitado de sus múltiples deseos, pero desconectado también de su yo; un yo sin yo, una identidad fragmentada. Zoila es en Fruta podrida un cuerpo sin órganos, cuyo único deseo es la muerte, el fin de todos los deseos, porque solo a través de la muerte puede ejercer su derecho a no consumir.

Mientras que su hermana, cliente preferente de la cultura de consumo, produce frutas, criaturas y deseos frenéticamente, y el médico acumula pacientes que llenen el vacío de otras muertes, abriéndolos y llenándolos de órganos que les permitan seguir funcionando y produciendo, Zoila entrega sus órganos y deseos a la putrefacción. Para fortalecer esta imagen, reproduce en un relato aterrador la historia de una anciana pobre que, según avanza la enfermedad, va viendo desaparecer partes de su cuerpo, primero un dedo, luego un pie, luego otro, después la pierna, y así sucesivamente, hasta que pide, clama, exige la muerte. Pero ya se ha entregado al hospital y el médico se la impide, hasta que un día, por fin, amanece muerta, y nunca se había visto "un cadáver tan sonriente" (63). Indiferente a su posible destino, Zoila se niega a convertirse en consumidora de órganos, rechaza desde un primer momento la llegada de un páncreas que no debería tener precio. Al convertirse en un cuerpo sin órganos, un monstruo anormal, Zoila, como potencial consumidora adquiere, a través del no, el poder: el control de sí misma y de sus acciones.

\section{Conclusión}

Según se ha visto en las obras analizadas, la producción de Meruane se interna en el valle de los monstruos, indaga en todos los rincones donde pueden acechar: 
extranjeros, anormales, videntes y enfermos, todos encuentran un lugar en las páginas de la narradora chilena. Estos monstruos tienen en común un absoluto desprecio por un sistema social, político y económico que los limita y los controla; por eso, se defienden, desconfiados y alerta ante cualquier nueva arma, mecanismo o tecnología con la capacidad suficiente como para incrementar ese abrazo no deseado. Niñas y adolescentes, desobedientes y en busca de una identidad que pugna por no ser diseñada, pueblan sus cuentos y narraciones. La huida resulta ser la única salida. Pero en un mundo globalizado, la huida también se convierte en un viaje circular que vuelve de nuevo al comienzo, por eso la única forma de escapar acaba por ser la muerte. Mártires ficcionales de un mundo real, Hildegreta, Hildeblanca y Zoila claman por revertir las normas de un mundo gobernado por verdaderos monstruos: aquellos que, ciegos, han aprendido a desear todo lo que el mercado ha decidido lanzarles, obedeciendo sus leyes suicidas, convirtiéndose en engranajes de una maquinaria que consume su humanidad. Los personajes sucumben ante su destino, pero su mensaje todavía existe y resiste, su monstruosa obra todavía advierte, anclándose en la identidad original del monstruo y sus habilidades videntes.

\section{Referencias bibliográficas}

Anderson, Simon G. et al. "Socioeconomic Deprivation Independently Predicts Symptomatic Painful Diabetic Neuropathy In People With Type 2 Diabetes", Journal Of Diabetes Nursing, vol. 20, Issue 10, nov., 2016, pp. 376-379.

Bacchilega, Christina. Postmodern Fairy Tales: Gender and Narrative Strategies. Philadelphia: University of Pennsylvania Press, 1997.

Bataille, Georges. L'Érotisme. N.p.: Ed. de Minuit, 2007.

Beverley, John. Subalternity and Representation: Arguments in Cultural Theory. Durham: Duke University Press, 1999.

Breton Le Breton, David, Marta Melero Gómez y Daniel Borrillo, "Lo imaginario del cuerpo en la tecnociencia”, Reis. Revista Española de Investigaciones Sociológicas, n. 197, 1994. Disponible en: http://www.jstor.org/stable/i40005532

Carcamo-Huechante, L.E., "Milton Friedman: Knowledge, Public Culture, and Market Economy in the Chile of Pinochet", Public Culture, vol. 18, n. 2, 2006, pp. 413-436.

Cortázar, Julio, "Algunos aspectos del cuento", Cuadernos Hispanoamericanos, n. 255, 1971, pp. 403-406.

Deleuze, Gilles y Félix Guattari, "The desiring machine”, en Anti-Oedipus: Capitalism and Schizophrenia. Minneapolis: University of Minnesota Press, 1983.

Edwards, Justin y Rune Graulund. Grotesque. [Electronic Resource]. N.p.: Hoboken: Taylor and Francis, 2013.

Epple, Juan Armando, "La nación ausente en la nueva narrativa femenina chilena", en Mabel Moraña y Javier Campos (ed.). Ideologías y literatura: Homenaje a Hernán Vidal. Pittsburg: Biblioteca de América, 2006.

Foucault, Michel. The Political Technology of Individuals. En Michel Foucault. Power: Essential Works of Foucault 1954-1984. New York: The New Press, 2000.

González, Elena y Eliana Ortega. La sartén por el mango: encuentro de escritoras latinoamericanas. Río Piedras: Ediciones Huracán, 1985.

Grimm, Jacob y Wilhelm Grimm. Cuentos. Edc. María Teresa Zurdo. Madrid: Cátedra, 2005. 
Haase, Donald. The Greenwood Encyclopedia of Folktales and Fairy Tales. N.p.: Westport, Conn.: Greenwood Press, 2008.

Haraway, Donna. Simians, Cyborgs and Women: The Reinvention Of Nature. London: Free Association, 1991.

Hutcheon, Linda. A Poetics of Postmodernism: History, Theorym Fiction. London/New York: Routeledge, 1988.

Illich, Ivan. Nemesis médica. La expropiación de la salud. N.p: Barral Editores, 1975.

Irigaray, Luce. Espéculo de la otra mujer. Trad. de Raúl Sánchez Cedillo. Madrid: Akal, 2007.

Jeftanovic, Andrea. Hablan los hijos: discursos y estéticas de la perspectiva infantil en la literatura contemporánea. Santiago de Chile: Editorial Cuarto Propio, 2011.

Manzi Cembriano, Jorge, "Experimentalismos en la novela chilena reciente. La ilegibilidad como estilo", en Macarena Areco. Cartografía de la novela chilena reciente: realismos, experimentalismos, hibridaciones y subgéneros. Santiago: CEIBO Ediciones, 2015.

Meruane, Lina. Las infantas. Santiago de Chile: Editorial Planeta Chilena, 1998.

-Cercada. Santiago Chile: Editorial Cuarto Propio, 2000.

-Fruta podrida. Santiago de Chile: FCE, 2007.

Noemi Voionmaa, Daniel, "La narrativa de Lina Meruane. Literatura, incertidumbre, resistencia", en M.B. Llanos y Ana M. Goetschel. Fronteras de la memoria: cartografías de género en artes visuales, cine y literatura en las américas y españa. Santiago Chile: Editorial Cuarto Propio, 2012.

Nouzeilles, Gabriela. Ficciones somáticas: naturalismo, nacionalismo y políticas médicas del cuerpo (Argentina 1880-1910). Rosario: Beatriz Viterbo, 2000.

Ojeda Franco, Mónica, "Pornoerótica latinoamericana: subversión en la narrativa de mujeres en el exilio", Anales de Literatura Hispanoamericana, vol. 43, 2014.

Osorio Tejeda, Nelson, "Ficción de oralidad y cultura de la periferia en la narrativa mexicana e hispanoamericana actual”, en Karl Kohut (ed.). Literatura mexicana hoy: del 68 a la Revolución. Frankfurt/Madrid: Vervuert/Iberoamericana, 1996, pp. 243-252.

Propp, Vladimir. Morphology of The Folktale. Trans. of Laurence Scott. Austin: University of Texas Press, 1968.

Rabkin, Eric S. Fantastic Worlds: Myths, Tales, and Stories. New York: Oxford University Press, 1979.

Rodríguez, Ana, "Las enfermedades de Lina Meruane", The Clinic Online, 4 de febrero, 2013. Disponible en: http://www.theclinic.cl/2013/02/04/las-enfermedades-de-linameruane/

Różycki, Tomasz. Colonias. Trad. de Xavier Farré. Madrid: Vaso Roto, 2015.

Spivak, Gayatri Chakravorty y Rosalind C. Morris. Can The Subaltern Speak?: Reflections on The History Of An Idea. New York: Columbia University Press, 2010.

Tatar, María. The Hard Facts of The Grimm's Fairy Tales. Princeton: Princeton University Press, 2003.

Valenzuela, Luisa. Cuentos completos y uno más. Pról. de Gustavo Sainz. México: Alfaguara, 1999.

-Peligrosas palabras: Reflexiones de una escritora. México: Océano, 2002.

Zipez, Jack. Fairy Tales and The Art of Subversion: The Classical Genre for Children and The Process of Civilization. New York: Routledge, 1991. 